\title{
Study on Laminar Two-Dimensional Lid-Driven Cavity Flow with Inclined Side Wall
}

\author{
Ramesh Chandra Mohapatra \\ Mechanical Department, Government College of Engineering, Keonjhar, India \\ Email: rameshmohapatra75@gmail.com
}

Received 21 February 2016; accepted 7 March 2016; published 11 March 2016

Copyright (C) 2016 by author and OALib.

This work is licensed under the Creative Commons Attribution International License (CC BY). http://creativecommons.org/licenses/by/4.0/

(c) (i) Open Access

\begin{abstract}
In this present work, a computational code is developed to solve a laminar two-dimensional lid driven cavity flow with inclined side wall. SIMPLE (Semi-Implicit Method for Pressure-Linked Equation) algorithm based on finite volume method on staggered grid has been used. Differed QUICK (Quadratic Upstream Interpolation for Convective Kinematics) schemes have been implemented for all calculations. The results are presented for inclination angle $\beta=30^{\circ}, 45^{\circ}$ and $\operatorname{Re}=100,1000$ and are compared with Demirdzic et al. benchmark solution. By comparison, it is found that the results are in very good agreement with the benchmark solution for $\mathrm{Re}=100$. But the results are close to the benchmark solution for $\operatorname{Re}=\mathbf{1 0 0 0}$.
\end{abstract}

\section{Keywords}

Laminar, Reynolds Number, Lid-Driven Cavity, Benchmark, Inclined Side Wall

Subject Areas: Mechanical Engineering

\section{Introduction}

For most fluid mechanics problems, the geometry of the problem cannot be represented by a Cartesian mesh. Instead, it is common for the boundaries to be curved in space. Some typical examples are turbine-blade passages, heat-exchangers, combustion chamber, aircrafts, vehicles, mixing vessels, flow around large structures like building, cooling towers, and air-conditioning systems. The need for the full Navier-Stokes simulation of complex fluid flows arises in numerous engineering problems. The method proposed by Patankar and Spalding [1] became very popular and is better known as the SIMPLE algorithm (Semi-Implicit Method for Pressure-Linked Equations). It is based on the finite volume descretization of Navies-stokes equations. Ghia et al. [2] solved lid driven cavity flow using finite difference vortices-stream function method using central difference approxima- 
tion. Many improvements to increase the convergence rate have been presented, and the version proposed by Van Doormaal and Raithby [3] is nowadays popular like SIMPLE. Van Doormal and Raithby's version is better known as the SIMPLEC algorithm where C refers to the word consistent. Maliska and Raithby [4] described an economical method of solving the equations of motion for two and three dimensional problems using nonorthogonal boundary-fitted mesh. The works of Ostrach [5] have shown the importance of the inclined cavity. The coordinate transformation technique advanced by Thompson et al. [6] is used for the solution of problems over complex geometries. The transformation is obtained from the solution of some partial differential equations on the regular computational domain. Demirdzic et al. [7] solved lid driven cavity flow by inclining the side walls using SIMPLE algorithm. It is similar to driven cavity flow, but the geometry is a parallelogram rather than a square. In this case the skewness of the geometry can be easily changed by changing the skew angle. It is a perfect test case for body fitted non-orthogonal grids and yet it is as simple as the cavity flow in terms of programming point of view. The deferred correction scheme of Hayase et al. [8] uses a first order upwind scheme with a third order correction.

\section{Lid-Driven Cavity Flow with Inside Side Wall}

We consider the steady flow inside an inclined cavity whose upper lid is moving at constant velocity $U$. This classical problem has become a standard benchmark for assessing the performance of algorithms to solve the incompressible Navier-Stokes equations. The benchmark solution of Demirdzic et al. [7] provide a tool to check the accuracy of present solution in handling complex flows in a non-orthogonal grid. The domains of calculations are a parallelogram with angle $=45^{\circ}$ and $=30^{\circ}$. In both cases, lid velocity $U=1$, cavity length $L=1$ and $\operatorname{Pr}$ $=0.71$. The geometry and the corresponding boundary conditions are shown in Figure 1 .

\section{Results and Discussions}

To test the implementation of the non-orthogonal differencing schemes the code is used to solve the problem of two dimensional lid-driven cavity flow with inclined side wall provided as a benchmark test case by Demirdzic et al. [7]. The results are shown for Reynolds number 100 and 1000 for wall angle $\beta=45^{\circ}$ and $\beta=30^{\circ}$, using the deferred QUICK scheme of Hayase et al. [8]. The solution field is calculated using a mesh of $81 \times 81$ for $\operatorname{Re}=$ 100 and $101 \times 101$ for $\mathrm{Re}=1000$ and uniform grids are employed. The value of pressure under-relaxation factor $\alpha_{p}$ is taken as 0.05 for $\operatorname{Re}=100$ and 0.01 for $\operatorname{Re}=1000$. The pseudo time step $\Delta \tau$ is used as 0.01 for $\operatorname{Re}=100$ and 1000 . The $u$ velocity profile along the vertical centerline of the cavity and $v$ velocity profile along the horizontal centerline is shown in Figure 2 with the benchmark solutions of Demirdzic et al. [7] being included for comparison. The results are in good agreement with the benchmark solution for $\mathrm{Re}=100$. But the results are close to the benchmark solutions for $\mathrm{Re}=1000$. If the mesh size is increased, then solutions may match with the results of Demirdzic et al. for $\mathrm{Re}=1000$. Figure 3 to Figure 6 show the stream line and other contours for Re $=100$ and $\operatorname{Re}=1000$ and also for $\beta=30^{\circ}$ and $\beta=45^{\circ}$ respectively. It is seen from these contour figures that the solution obtained are very smooth without any wiggles in the contours. As Re increases from 100 to 1000 , the

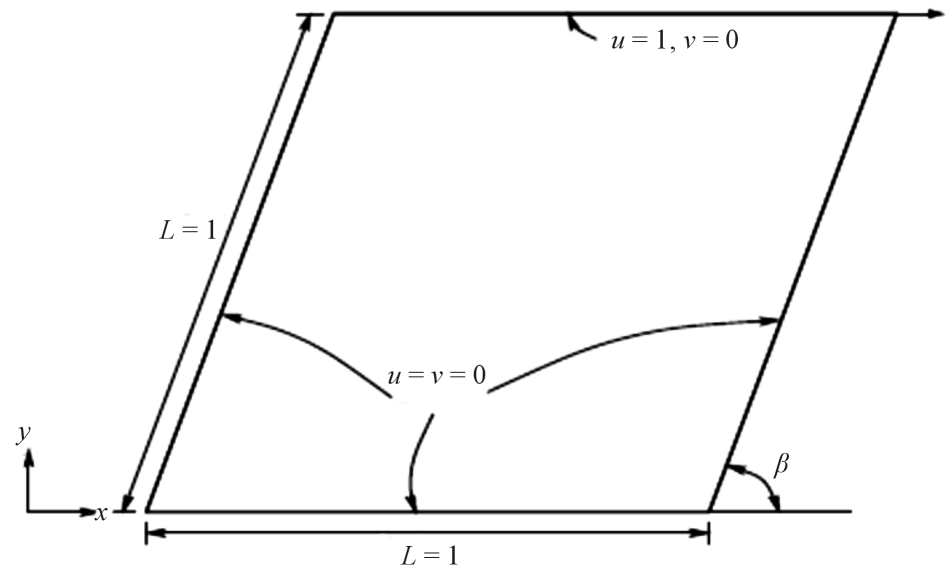

Figure 1. Geometry and corresponding boundary condition of the problem. 


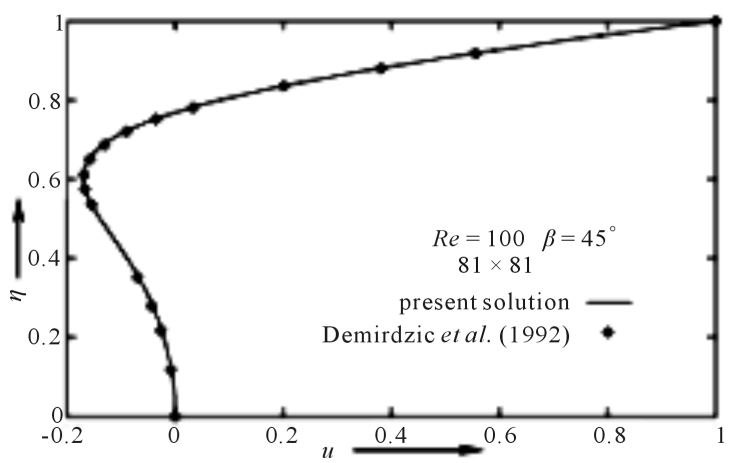

(a)

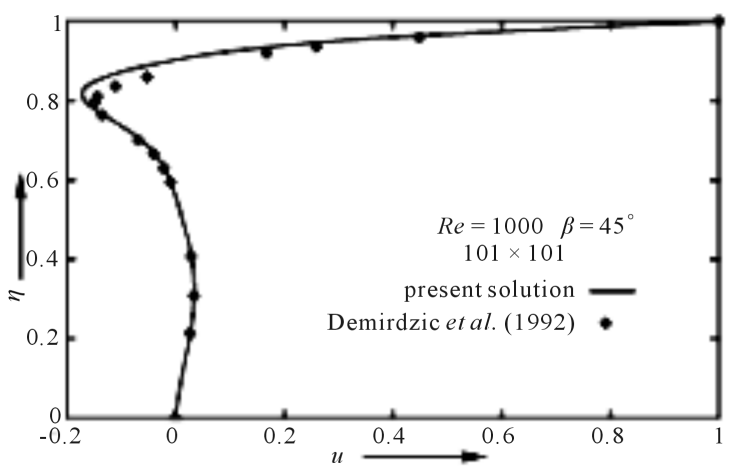

(c)

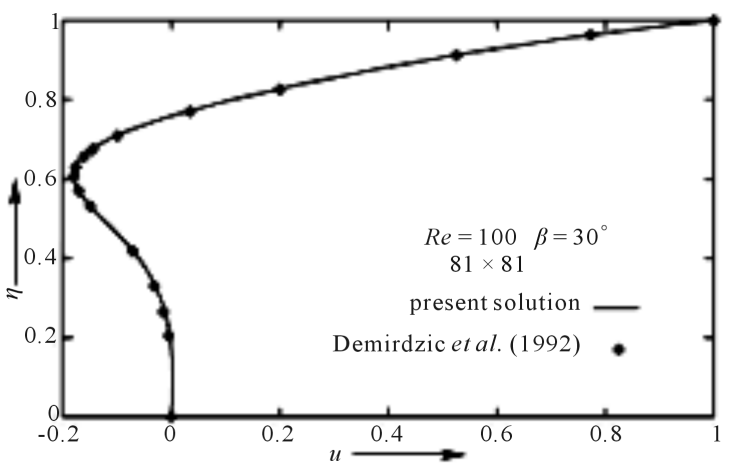

(e)

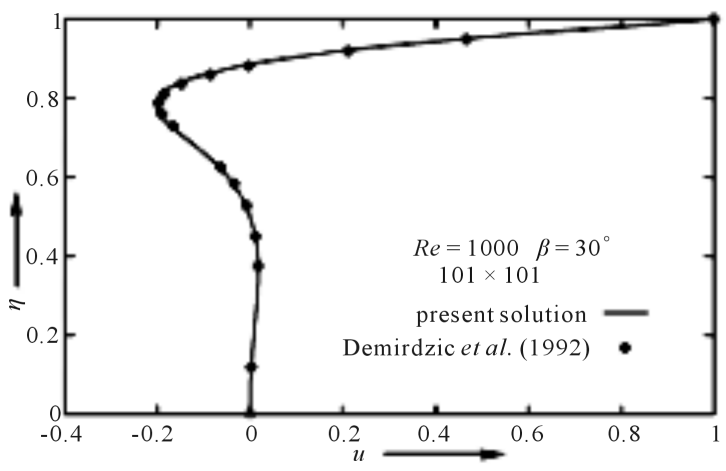

(g)

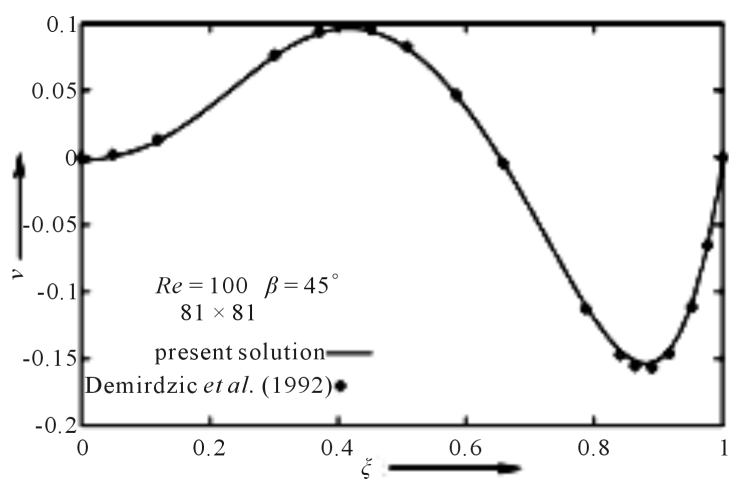

(b)

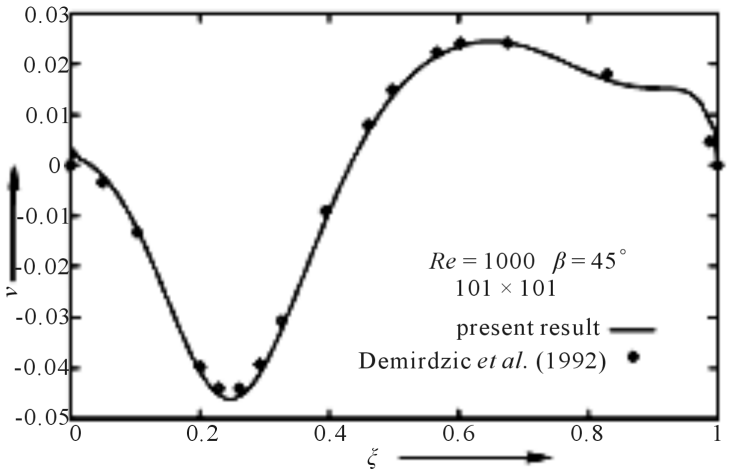

(d)

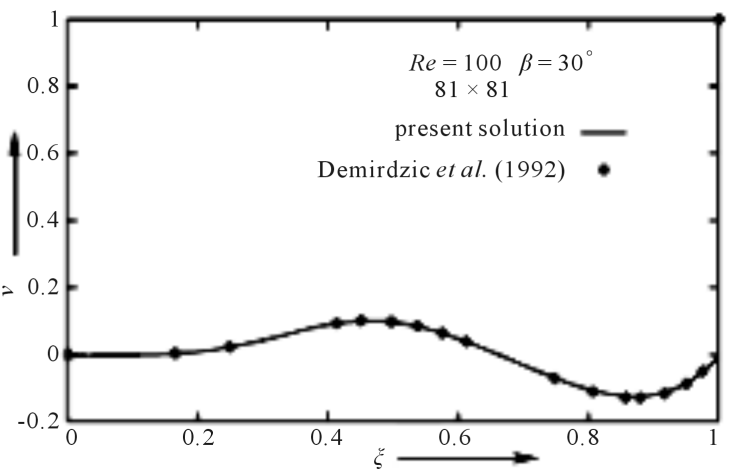

(f)

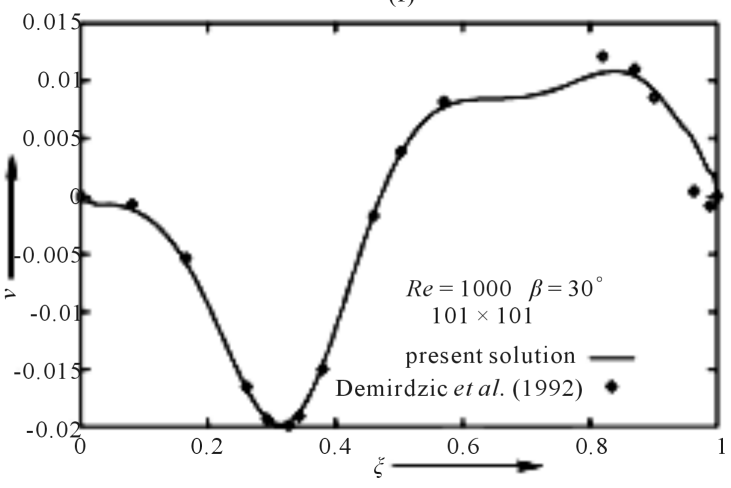

(h)

Figure 2. Comparison with $u$ and $v$ velocity with Demirdzic et al. [7]. $u$ : velocity along vertical centre-line; $v$ : velocity along horizontal centre-line. 


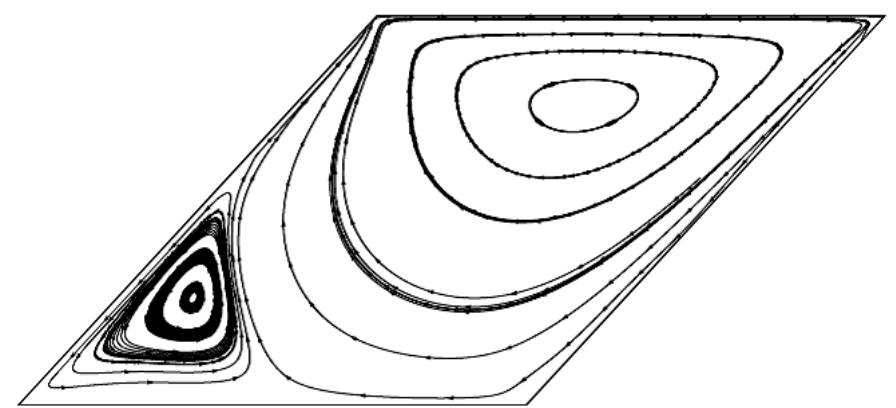

(a)

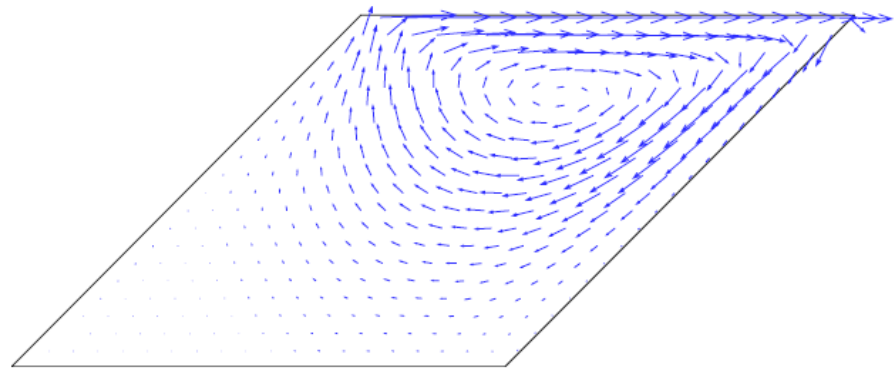

(b)

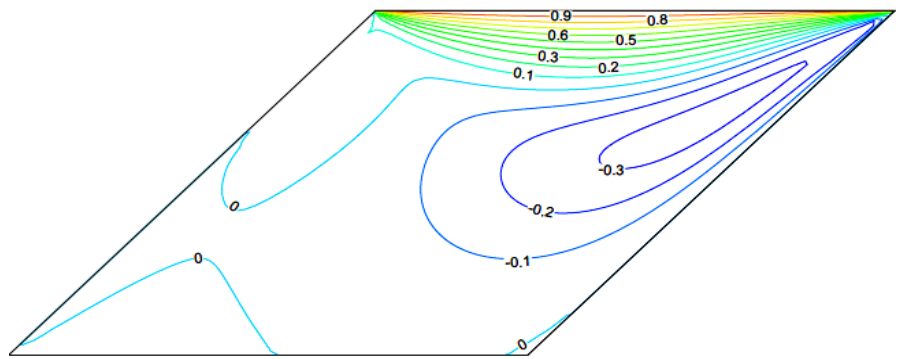

(c)

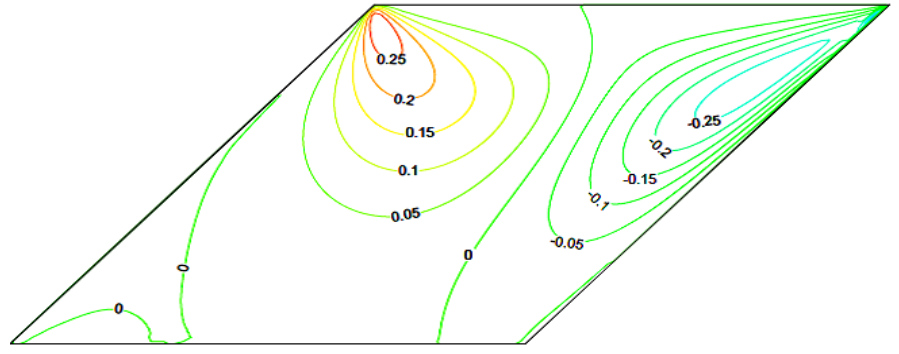

(d)

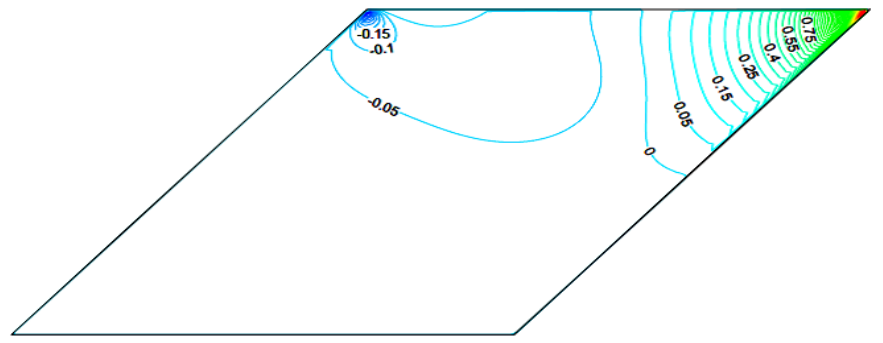

(e)

Figure 3. $\operatorname{Re}=100$ and $\beta=45^{\circ}$. (a) Stream line; (b) Vector; (c) $u$ contour; (d) $v$-contour; (e) $p$-contour. 


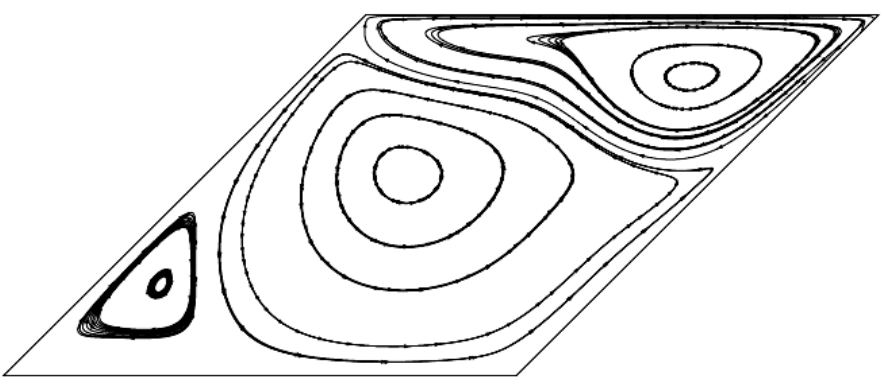

(a)

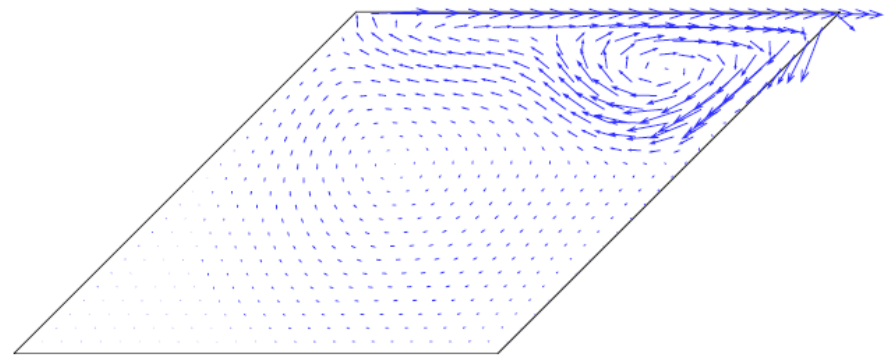

(b)

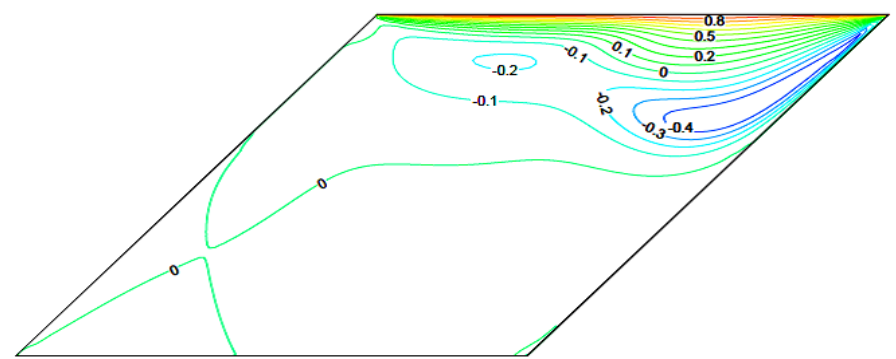

(c)

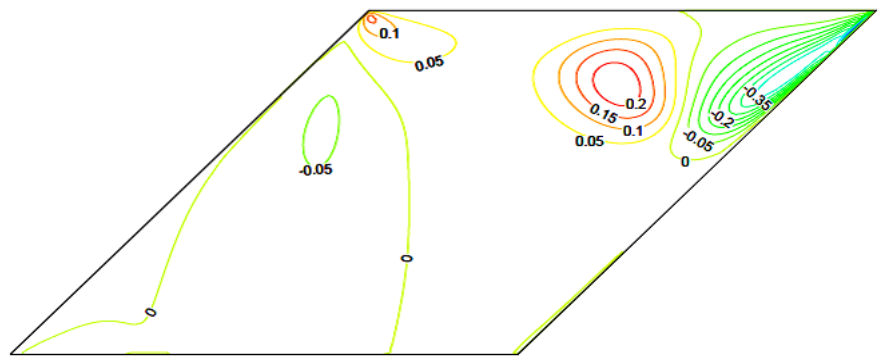

(d)

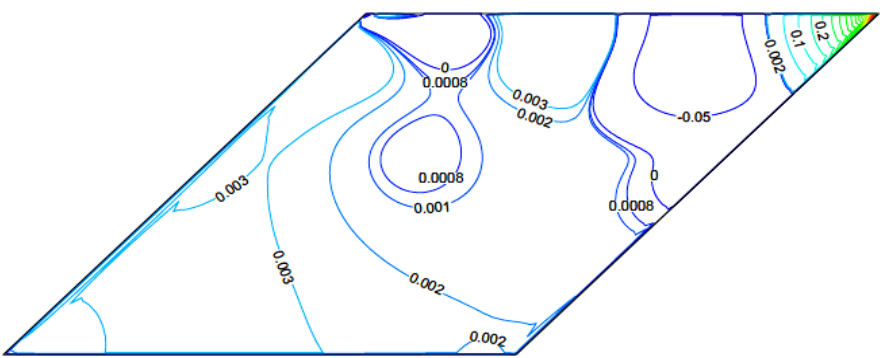

(e)

Figure 4. $\operatorname{Re}=1000$ and $\beta=45^{\circ}$. (a) Stream line; (b) Vector; (c) $u$ contour; (d) $v$-contour; (e) $p$-contour. 


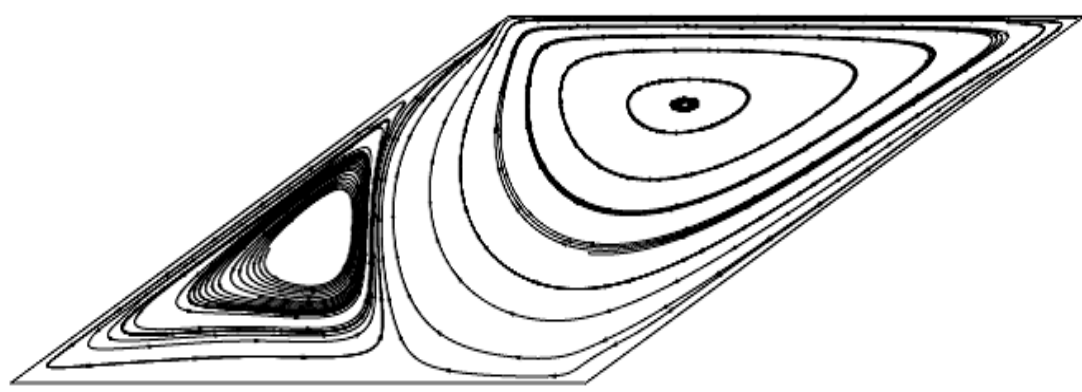

(a)

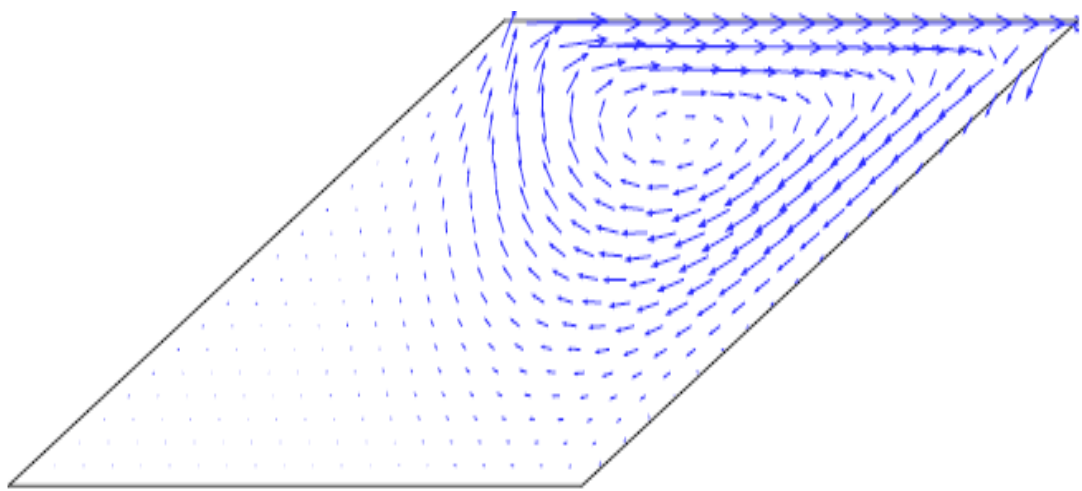

(b)

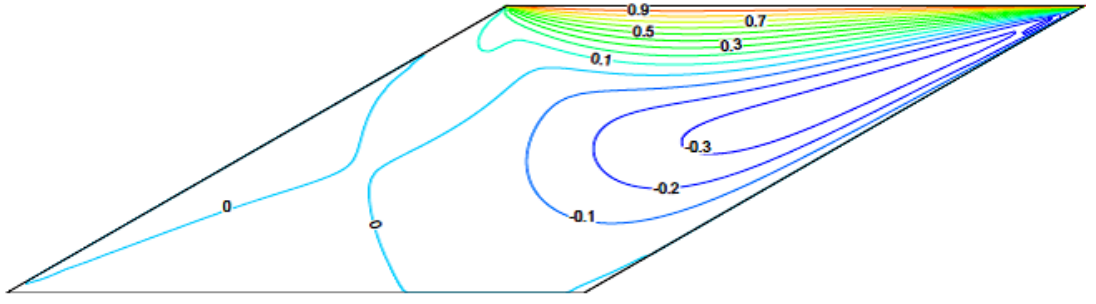

(c)

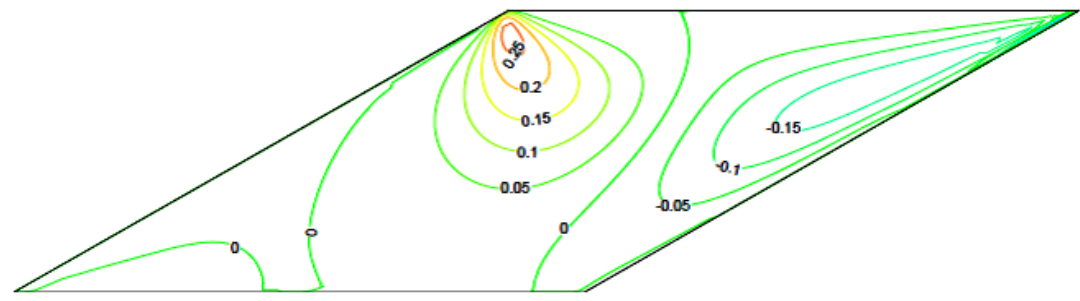

(d)

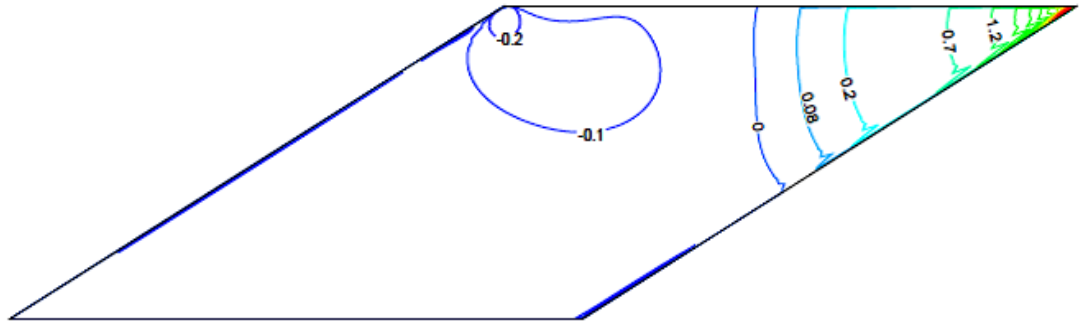

(e)

Figure 5. $\operatorname{Re}=100$ and $\beta=30^{\circ}$. (a) Stream line; (b) Vector; (c) $u$-contour; (d) $v$-contour; (e) $p$-contour. 


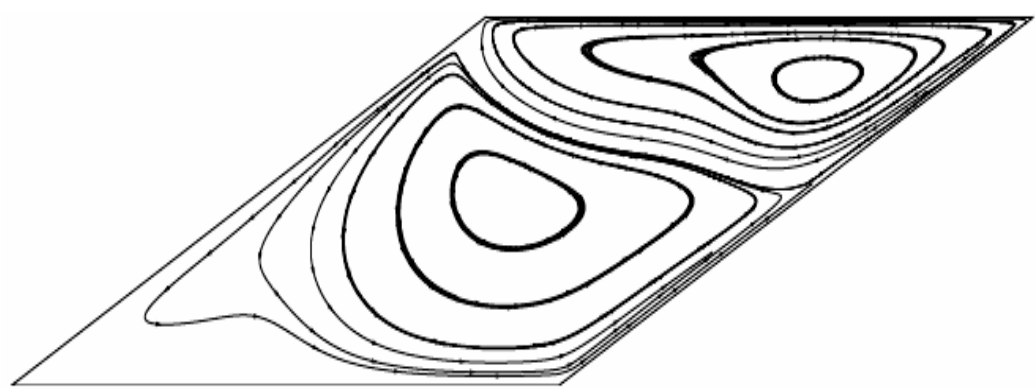

(a)

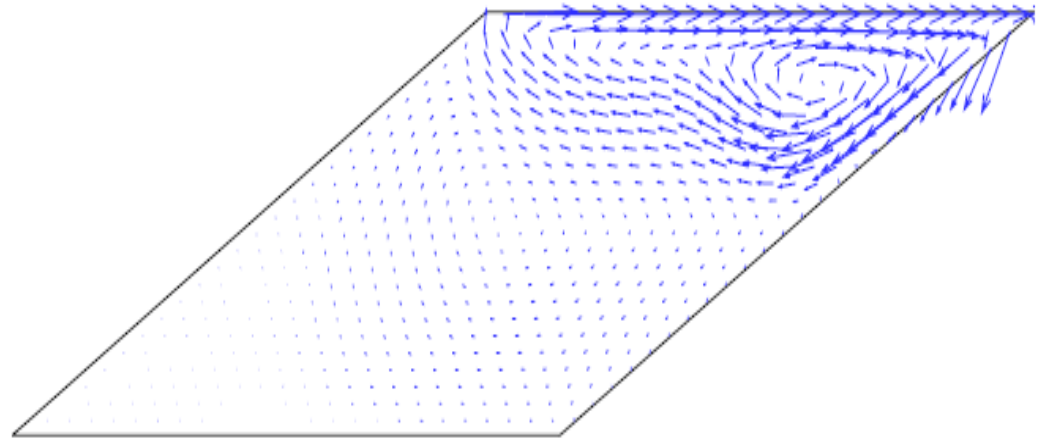

(b)

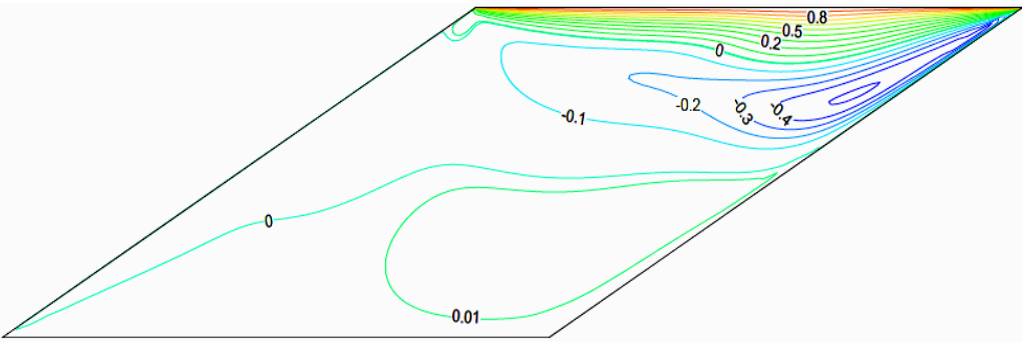

(c)

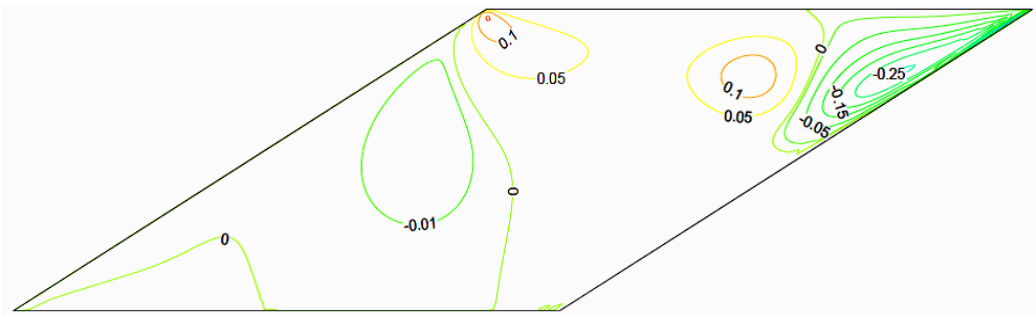

(d)

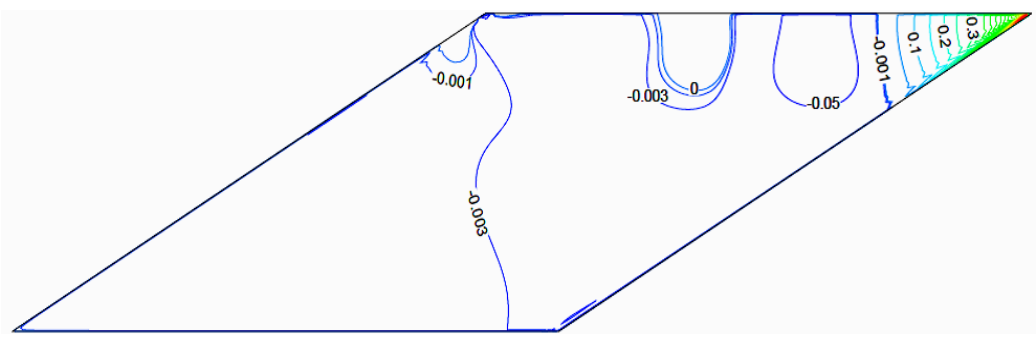

(e)

Figure 6. $\operatorname{Re}=1000$ and $\beta=30^{\circ}$. (a) Stream line; (b) Vector; (c) $u$-contour; (d) $v$-contour; (e) $p$-contour. 
secondary vertices starts developing at left corner of the cavity and go larger in magnitude. All secondary vertices appear initially very near to the left corner of the cavity and go larger in magnitude. It is also interesting to point out from Figure 3 to Figure 6 that for both $\mathrm{Re}=100$ and $\mathrm{Re}=1000$ the strength of the vortices at the centre of the primary vortex decreased as the inclination angle increases from $\beta=30^{\circ}$ to $\beta=45^{\circ}$. On the other hand the value of the stream function start to increase as the inclination angle increases.

\section{Conclusion}

SIMPLE algorithm for complex geometry using non-orthogonal grid was described. To test the code it was used to solve the problem applied to lid driven cavity with inclined side wall and results were compared with the benchmark solution of Demirdzic et al. [7]. The results for $\operatorname{Re}=100$ and $\beta=45^{\circ} \& 30^{\circ}$ were in good agreement with the benchmark solution. But $u$ velocity along vertical centerline for $\operatorname{Re}=1000 \& \beta=45^{\circ}$ and $v$ velocity along horizontal centerline for $\operatorname{Re}=1000 \& \beta=30^{\circ}$ did not match with the benchmark solution for $101 \times 101$ mesh size.

\section{References}

[1] Patankar, S.V. (1980) Numerical Heat Transfer and Fluid Flow. Hemisphere Publishing Co., New York.

[2] Ghia, U., Ghia, K.N. and Shin, C.T. (1982) High-Re Solutions for Incompressible Flow Using the Navier-Stokes Equations and a Multigrid Method. Journal of Computational Physics, 48, 387-411. http://dx.doi.org/10.1016/0021-9991(82)90058-4

[3] Van Doormall, J.P. and Raithby, G.D. (1984) Enhancements of the Simple Method for Predicting Incompressible Fluid Flows. Numerical Heat Transfer, 7, 147-163.

[4] Maliska, C.R. and Raithby, G.D. (1984) A Method for Computing Three Dimensional Flows Using Non-Orthogonal Boundary-Fitted Co-Ordinates. International Journal for Numerical Methods in Fluids, 4, 519-537. http://dx.doi.org/10.1002/fld.1650040606

[5] Ostrach, S. (1988) Natural Convection in Enclosures. Journal of Heat Transfer 50th Anniversary Issue, 110, 11751190. http://dx.doi.org/10.1115/1.3250619

[6] Thompson, J.F., Warsi, Z.U.A. and Mastin, C.W. (1985) Numerical Grid Generation. North Holland.

[7] Demirdzic, I., Lilek, Z. and Peric, M. (1992) Fluid Flow and Heat Transfer Test Problems for Non-Orthogonal Grids: Bench-Mark Solutions. International Journal for Numerical Methods in Fluids, 15, 329-354. http://dx.doi.org/10.1002/fld.1650150306

[8] Hayase, T., Humphrey, J.C. and Greif, R. (1992) A Consistently Formulated QUICK Scheme for Fast and Stable Convergence Using Finite-Volume Iterative Calculation Procedures. Journal of Computational Physics, 98, 180-118. http://dx.doi.org/10.1016/0021-9991(92)90177-Z

\section{Nomenclatures}

Re: Reynolds number

Pr: Prandtl number

Nu: Nusselt number

$\beta$ : Volumetric expansion coefficients

$\alpha_{p}$ : Pressure under-relaxation factor

SIMPLE: Semi-implicit method for pressure-linked equation

SIMPLEC: Semi-implicit method for pressure-linked equation consistent

QUICK: Quadratic upstream interpolation for convective kinematics 